\title{
El beneficio del oro en minerales refractarios de la Faja Pirítica
}

\author{
S. del Barrio Martín ${ }^{(1)}$, R. Martínez Orio(1), A. Sánchez ${ }^{(2)}$ \\ (1) Instituto Geológico y Minero de España (IGME). Departamento de Investigación en Recursos Geológicos. \\ 28003 Madrid, España. \\ s.delbarrio@igme.es; ro.martinez@igme.es
}

(2) Equipo de investigadores del Proyecto de Investigación: Historia empresarial, mercados y desarrollo productivo en la minería española contemporánea.

http://www.um.es/hisminas

\begin{abstract}
RESUMEN
La Faja Pirítica Ibérica, en la que se ubican más de 70 yacimientos de sulfuros masivos volcanogénicos, constituye una provincia metalogenética a escala mundial, con unos recursos considerables en azufre, hierro y metales básicos y en menor medida oro y plata. El Instituto Geológico y Minero de España (IGME), en el sector de las investigaciones minero-metalúrgicas, ha participado en diversos proyectos encaminados a la recuperación del oro de este tipo de mineralizaciones. Una buena parte de su labor investigadora, en el ámbito de la hidrometalurgia, se ha centrado en la búsqueda de tratamientos alternativos de las menas auríferas refractarias, tan características de la Faja Pirítica, contemplando simultáneamente la recuperación de los metales básicos y del oro contenido en dichas menas, así como la extracción de cualquier otro metal minoritario, susceptible de beneficio económico, que pudiera contribuir a la reducción de los costes de explotación. A tal fin, se han combinado métodos de tratamiento tradicionales, como la cianuración, con otros de carácter innovador, tales como la lixiviación ácida a presión, la tostación oxidante, la lixiviación férrica a presión atmosférica y la biolixiviación.
\end{abstract}

Palabras clave: Biolixiviación, cianuración, Faja Pirítica, hidrometalurgia, oro.

\section{Gold production from refractory minerals in the Pyritic Belt}

\begin{abstract}
The Pyritic Belt is a world class metalogenetic province, with more than 70 known deposits of volcanogenic massive sulphides. These deposits contain relevant resources of sulphur, iron, basic metals and, to a lesser extent, gold and silver. The Spanish Geological Survey (IGME) has recently played a main role in several activities related to the research, exploration and production of gold. As a part of this public research, some of the developments of IGME in the field of hydrometallurgy have been dedicated to the alternative treatment of refractory gold ores, which are quite abundant in the Pyritic Belt. These treatments aim to recover the gold contained in such ores, plus the extraction of any other metal that may lead to an economic benefit, thus reducing production costs. To achieve this goal, some traditional treatments such as cyanidation may be used in combination with innovative ones, such as high pressure acid leaching, oxidizing roasting and bioleaching.
\end{abstract}

Keywords: bioleaching, cyanidation, hydrometallurgy, gold, Pyrite Belt.

\section{ABRIDGED ENGLISH VERSION}

\section{Introduction}

Gold exists in Nature both as a native element and as a part of alloys, together with silver and trace elements such as copper, antimony, mercury, bismuth and, very rarely, platinum group metals. There are several typology classifications for gold deposits based on genetic theories, morphology, geochemical signatures, etc. either for deposits where the gold is the main ore or where it is a co-product, but this article will only refer to 
S. del Barrio Martín, et al., 2019. El beneficio del oro en minerales refractarios de la Faja... Boletín Geológico y Minero, 130 (2): $341-359$

the gold contained in the massive iron-sulphide deposits and basic metals in volcano - sedimentary formations.

Gold is not usually released in the iron-sulphide matrix and if it is, the gold grains are very rare. Pyrite is the sulphide most frequently associated with gold. Gold appears in the pyrite as a solid dissolution or as an extremely fine grain, constituting the so-called "invisible gold", or as a visible gold forming blisters of solutions, inclusions, micro veins...

Historically, the high value of the ore led to the mining of the most accessible deposits with the highest concentrations and the easiest to extract. Exhaustion of these deposits made new prospection techniques possible, metallurgy advances that have permitted the location of hidden deposits, the mining of low concentration deposits and the extraction of invisible gold.

For centuries, gold recovery was developed by gravimetric methods that took advantage of the high density of the metal, through amalgamation and recovery via the fusion of copper and lead metals. At the end of the $19^{\text {th }}$ Century, in order to treat more complex mineralization and lower concentrations, chlorination, cyanidation and electrochemical methods started to be developed as hydrometallurgy procedures. Nowadays, cyanidation is the key tool in the processing of these minerals. When conventional cyanidation leads to poor recovery, i.e. less than $80 \%$ of the gold contained, the mineral is classified as refractory (La Brooy et al., 1994).

Following different parameters (mineralogy, structure, genetics...), there are different classifications for mineralization, with the one used for this study being based on valuable metal contents, specifically Au-Ag:

- Pyritic mineral, containing the following basic metals: $\mathrm{Cu} 0.7 \%, \mathrm{~Pb} 0.8 \%, \mathrm{Zn} 1.3 \%$, low gold $(0.3 \mathrm{~g} / \mathrm{t})$ and silver (33 g/t) It exists both in massive and disseminated structures and stockworks. Massive mineralization is the most common and holds most available resources in large deposits.

- Complex mineral, with the following average contents: Cu 0.8\%, Pb 1.2\%, Zn 3.8\%; Au contents vary from $0.5 \mathrm{~g} / \mathrm{t}$ to $1 \mathrm{~g} / \mathrm{t}$ and $\mathrm{Ag}$ between 55 and $60 \mathrm{~g} / \mathrm{t}$. Present in massive, banded and disseminated structures, mainly in the northern band of the belt.

- Copper mineral, average values of: $\mathrm{Cu} 2.1 \%, \mathrm{~Pb} 0.18 \%, \mathrm{Zn} 0.65 \%$. Generally present in the central and lower sectors of massive deposits, and also in stockworks. Gold contents are between $0.2 \mathrm{~g} / \mathrm{t}$ and $1 \mathrm{~g} / \mathrm{t}$, with local values of $2 \mathrm{~g} / \mathrm{t}$ and $4 \mathrm{~g} / \mathrm{t}$. Copper contents may be as high as to be considered anomalous as in the World Class Neves Corvo deposit in the Portuguese Pyritic Belt.

Traditional production of gold in the Pyritic Belt took place in limonitic gossans, mostly depleted nowadays. Copper mineral was partially exploited at the end of the $20^{\text {th }}$ Century. Moreover, gold was also recovered as a byproduct in the ashes of Pyrite roasting, but this resource is no longer available. Gold in the complex mineral is usually recovered at the end of the metallurgy process.

Despite the large exploitation of traditional resources that had higher gold and silver contents, huge volumes of massive pyrite and complex mineral still have a large potential for precious metals. New projects are oriented to recovering gold from complex ores with a low average content.

\section{Treatment of gold minerals}

Mineral characterization of a deposit is relevant for the processing methodology and for the efficiency of all the chemical processes involved in gold extraction. Each mineral is unique and the following factors are considered (Marsden and House, 2006):

- Minerals associated to gold

- Size distribution of the gold grains

- Mineralogy of the ore and the overburden

- Mineral associations

- Mineral alterations

- Variability of the above within the deposit or in time.

The modern gold industry uses sodium cyanide as the processing agent (Udupa et al., 1990), due to its great efficiency in the dissolution of gold, its accessibility and low cost. Despite the toxicity of cyanide, it can be safely used with very low risks for health and the environment. In general, cyanide is only used in oxidized zones, where sulphides have been converted to oxides. Gold minerals linked to lead, copper or zinc sulphides are first floated and the gold is later recovered through the refining of the impure metals.

Due to the difficult extraction of gold from refractory minerals, an oxidation treatment is required to free the gold encapsulated in them, allowing the gold to come into contact with the leaching reactive (Ballester, A.; Verdeja, L.; Sancho, J. 2000). Pyrometallurgical processes of sulphides and carbonated ores were used for decades, but nowadays are considered as too pollutant because of their significant sulphur-dioxide emissions. Because of environmental policies and in order to reduce operational and investment costs, hydrometallurgical processes are now considered as the most efficient alternative. 
S. del Barrio Martín, et al., 2019. El beneficio del oro en minerales refractarios de la Faja... Boletín Geológico y Minero, 130 (2): $341-359$

Leaching processes are usually carried out in autoclaves at different pressure and temperatures conditions. Most leaching processes at atmospheric pressure are developed in a sulphate environment. Ferric sulphate is widely used as a leaching agent in several hydrometallurgical processes because of the easy reduction of ferric salts to allow the oxidation of the other compounds. To reach high efficiency, a large concentration of ferric ions is necessary.

As previously stated, complex minerals of the Pyritic Belt have a significant gold and silver content, although this might be lost if the pyrite is treated as a waste. The waste of the leaching stage contains the sulphur, lead, silver and gold of the initial mineral, making the recovery of these metals possible.

\section{Hydrometallurgical research in IGME}

Part of the research and development work of IGME is active in the search for alternative treatments for the complex sulphides of the Pyritic Belt, in order to recover gold and other existing metals. Innovation and research development in hydrometallurgical treatments are necessary in the production of non-ferrous metals, mainly copper and zinc, from sulphides, based on chemical leaching and bioleaching. As a consequence of these studies, IGME, together with PROTON INGENIEROS, has developed a new hydrometallurgical process for the treatment of complex sulphides.

This process has the goal of designing a new plant for the treatment of copper and zinc sulphides. Leaching is done at atmospheric pressure in open reactors and at temperatures of 80 to $100^{\circ} \mathrm{C}$. This method allows the direct treatment of ores with a low content of copper and zinc, but also of global flotation concentrates. Leaching is a one-step process using ferric sulphate as the oxidizing agent for the sulphides. The difference with other existing processes is the recovery of the ferric ion, which takes place in an independent stage using fresh air for oxidation, thus keeping $\mathrm{pH}$ values between 4 and 5.5. This is considerably cheaper than using pure oxygen. Ammonia is used as neutralizer, as it is a cheap base that can be added continuously and under control and does not interfere in the quality of the final product. Afterwards, copper and zinc are extracted through solvents for electrolytic treatment.

\section{Discussion and conclusions}

The Pyritic Belt still holds extraordinary potential for metallic minerals. Taking advantage of this potential is directly linked to the capacity of recovering gold from refractory minerals. The way to increase recovery is the previous oxidation treatment of the sulphides, allowing leaching of the gold through contact with the cyanide, thus upgrading the final recovery.

The hydrometallurgical treatment could soon lead not only to the recovery of gold contained in the primary minerals of the Pyritic Belt, but also the precious metals contained in the wastes of the floating processes. The Spanish Geological Survey (IGME) has developed different research lines in order to optimize hydrometallurgical treatment in the last two decades. The advances achieved, both in the bioleaching and the oxidizing processes, allow IGME to face the near future in technological development with optimism.

\section{Introducción}

El oro, en la naturaleza, aparece de forma dominante en su estado nativo o en aleaciones, de las que es el principal componente, con plata, con trazas de otros metales, como cobre, antimonio, mercurio y bismuto, o más raramente con metales del grupo del platino. En la litosfera superior su abundancia es de 0,005 ppm, con una relación Au/Ag alrededor de 0,7. El contenido medio en las rocas ígneas es 0,004 ppm; en las sedimentarias 0,03 ppm para areniscas y conglomerados y 0,004 ppm para calizas. Algunos tipos de pizarras grafitosas, esquistos sulfurosos, fosforitas, areniscas y conglomerados pueden llegar a albergar 2 ppm, o incluso más (Boyle, 1987).

Los minerales auríferos, tales como los teleruros, antimoniuros y seleniuros, son raros y aún más infrecuentes los bismutiuros y los sulfuros auroargentíferos (Boyle, 1987), sin embargo, es muy común la presencia de inclusiones, puras o aleadas, en sulfuros de hierro y de metales básicos y en materiales carbonosos. Estas inclusiones pueden alcanzar tamaños microscópicos o distribuirse en forma atómica en la estructura cristalina del mineral que las alberga (Chen y Reddy 1990). Puesto que el oro nativo constituye la principal mena del metal, por la forma de presentarse, se establece una primera distinción entre oro visible, o libre, y oro invisible, sin que por supuesto exista una línea neta de separación entre ambas categorías y que implícitamente ya comporta la mayor o menor facilidad de su recuperación.

Existen numerosas clasificaciones tipológicas para 
los yacimientos auríferos, basadas en las teorías genéticas, morfologías, signaturas geoquímicas, etcétera, tanto si el oro constituye la mena principal, como si se trata de un coproducto (Boyle, 1987), pero para los fines de este trabajo nos vamos a restringir al oro contenido en los depósitos masivos de sulfuros de hierro y metales básicos, en formaciones vulcanosedimentarias.

\section{Mineralizaciones de oro asociado con sulfuros}

El oro no suele estar liberado en la matriz de los sulfuros de hierro, o puede ocurrir que esté liberado, pero a tamaños muy pequeños. La pirita es el sulfuro de hierro que más se asocia con oro. El oro aparece en la pirita como disolución sólida o extremadamente fina, constituyendo así el llamado oro invisible, o como oro visible formando ampollas de exsoluciones, inclusiones, microvenillas, relleno de intersticios, reemplazamientos. Es el mineral más común entre los sulfuros y está presente en todas las mineralizaciones sulfuradas. De igual manera, la marcasita, polimorfo de la pirita, puede contener inclusiones de oro. La pirrotina $\left(\mathrm{Fe}_{1-\mathrm{S}} \mathrm{S}\right)$ también puede presentar inclusiones de oro y tiende a oxidarse más fácilmente que la pirita. La arsenopirita (FeAsS) es el mineral que más se relaciona con el oro después de la pirita. Las asociaciones de oro en pirita y arsenopirita se han encontrado semejantes, aunque la concentración de oro puede ser mucho mayor en ésta última debido al mayor espacio inter-celda de la estructura molecular y la semejanza de condiciones de formación que presenta con el oro.

La figura 1 muestra de una manera general las diversas asociaciones del oro con los sulfuros (Madsen y House 2006).

- Oro liberado

- Cristales de oro en los intersticios de los granos.

- Granos de oro encapsulado en sulfuros locluido).

- Presencia de oro en granos de sulfuro

- Oro en micro fracturas de sulfuros.

- Oro en forma de partículas coloidales o en soluciones sólidas de sulfuro.

Para las asociaciones de oro 1, 2 y 3 , en la figura, el oro tiene más probabilidades de ser liberado. Aunque el tipo 3 sea refractario, es posible liberar el oro por molienda fina u oxidación. Contrariamente, para los tipos 5, 6, y posiblemente 4, el oro puede seguir sin liberarse incluso a tamaños finos. Actualmente se están procesando minerales conteniendo asociaciones del tipo 6 , donde los granos de oro son tan pequeños como $1 \mu \mathrm{m}$, y se encuentran dentro de una matriz de sulfuro. Generalmente, un tratamiento oxidante de estas mineralogías permite incrementar las extracciones de oro.

\section{Mineralurgia del oro}

Históricamente, el alto valor de la mena hizo que la minería del oro tuviera, más que en otras sustancias, el carácter de minería de las "bonanzas" y los "placeres" , es decir, se explotaban las concentraciones más accesibles, con las leyes más altas y de más fácil recuperación, cuyo agotamiento implicó, no solamente el desarrollo de las técnicas de prospección, sino también los avances en la mineralurgia y la metalurgia que han permitido la localización de yacimientos no manifiestos, la explotación de yacimientos de baja ley y la extracción del oro invisible. Un hito a escala mundial para la minería contemporánea del oro fue, en 1834, el descubrimiento de los yacimientos del White Waters Ridge, en Sudáfrica.

Durante siglos, la recuperación del oro se hizo fundamentalmente por métodos gravimétricos, aprovechando el elevado peso específico del metal, mediante la amalgamación y asimismo recobrándolo en la fusión de menas de cobre y plomo. Fue a finales del s. XIX cuando, para el tratamiento de mineralizaciones de composiciones más complejas y leyes más bajas, se empezó a recurrir a los procedimientos hidrometalúrgicos, como la cloruración y la cianuración, y electroquímicos.

En nuestros días, la cianuración es la pieza clave en el procesamiento de estos minerales Cuando la cianuración convencional produce pobres recuperaciones, inferiores al $80 \%$, el mineral se clasifica como refractario (La Brooy et al. 1994). Las estadísticas muestran que, en el mundo, 2/3 de los depósitos de oro pertenecen a minerales difíciles de procesar, estimándose que la tercera parte de la producción total de oro en el mundo proviene de estos minerales (Madsen y House, 2006; La Brooy et al. 1994)).

Cuando el oro esta encapsulado en sulfuros de hierro, principalmente pirita y arsenopirita, el cianuro y el oxígeno tienen muy poca superficie de contacto con las partículas de oro obteniéndose bajas recuperaciones. En estos casos, es necesario realizar un tratamiento previo de oxidación (pretratamiento) del sulfuro mineral que permita el contacto directo del oro con el reactivo de lixiviación (Ballester, Verdeja, Sancho, 2000). Entre las tecnologías utilizadas comercialmente se encuentran la oxidación a presión, la oxidación química, la tostación y la biolixiviación, entre otras. 


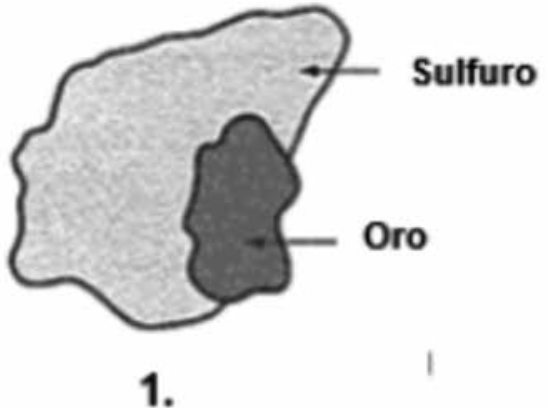

Sulfuro u otro material

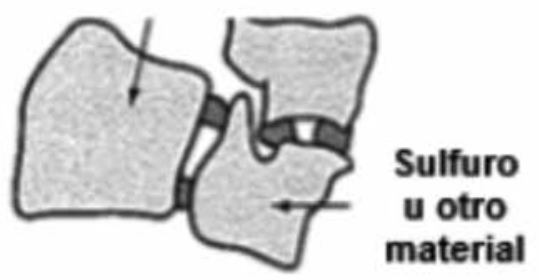

2.

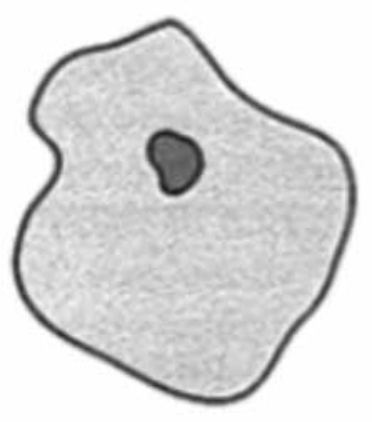

3.

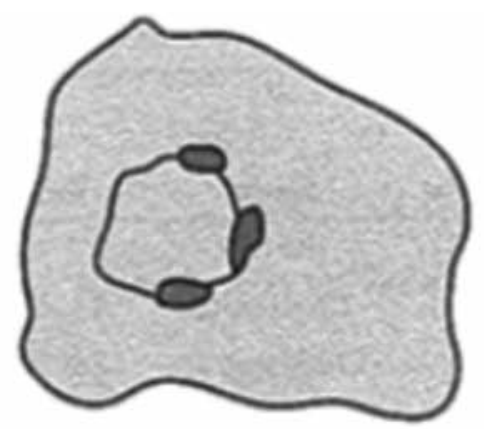

4.

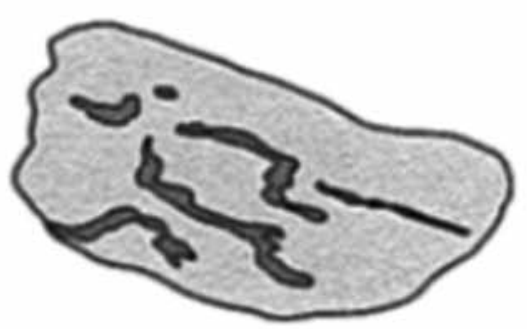

5.

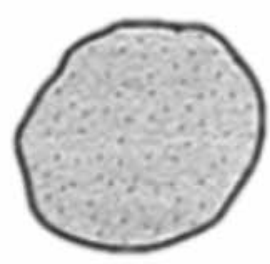

6.

Figura 1. Asociaciones de oro con sulfuros minerales (Madsen y House, 2006).

Figure 1. Gold associations to mineral sulphides (Madsen and House, 2006).

\section{La Faja Pirítica Ibérica (FPI) y sus mineralizaciones}

Este conjunto de formaciones vulcano-sedimentarias, con edades comprendidas entre el Devónico superior y el Carbonífero medio, constituyen la mayor parte del terreno tectono-estratigráfico denominado Zona Sud Portuguesa. Se extiende a lo largo de una banda de dirección ONO-ESE desde la costa atlántica portuguesa hasta el valle del Guadalquivir, con una longitud de $230 \mathrm{~km}$ y una anchura media de $35 \mathrm{~km}$. Figura 2.

En la Faja Pirítica se han explotado más de 70 yacimientos, durante los últimos cien años, de sulfuros masivos volcanogénicos de hierro y metales básicos, con contenidos apreciables de metales preciosos, de los que actualmente se estiman unos recursos de
$1.700 \mathrm{Mt}$, lo que unido a la existencia de más de diez depósitos con unas reservas superiores a los $50 \mathrm{Mt} \mathrm{le}$ confieren el carácter de provincia metalogenética a escala mundial. En esos recursos se individualizan 14,6 Mt de $\mathrm{Cu}, 13,0 \mathrm{Mt}$ de Pb, 34,9 Mt de Zn, $46.100 \mathrm{t}$ de Ag y 880 t de Au (Leistel et al 1998). Los contenidos medios de un yacimiento tipo son: $44-48 \%$ S, 39-44\% $\mathrm{Fe}, 2-6 \% \mathrm{Cu}+\mathrm{Pb}+\mathrm{Zn}, 5-30 \mathrm{~g} / \mathrm{t} \mathrm{Ag}$ y $0.2-1.5 \mathrm{~g} / \mathrm{t} \mathrm{Au}$.

Atendiendo a conceptos genéticos, mineralógicos, estructurales, de alteraciones, etc., son diversas las clasificaciones establecidas para las mineralizaciones, aunque para los fines de este trabajo se va a seguir el criterio de los contenidos en los metales beneficiables, con incidencia en la asociación Au-Ag. Hemos de tener en cuenta que dentro de cada depósito pueden presentarse varios tipos de mineraliza- 


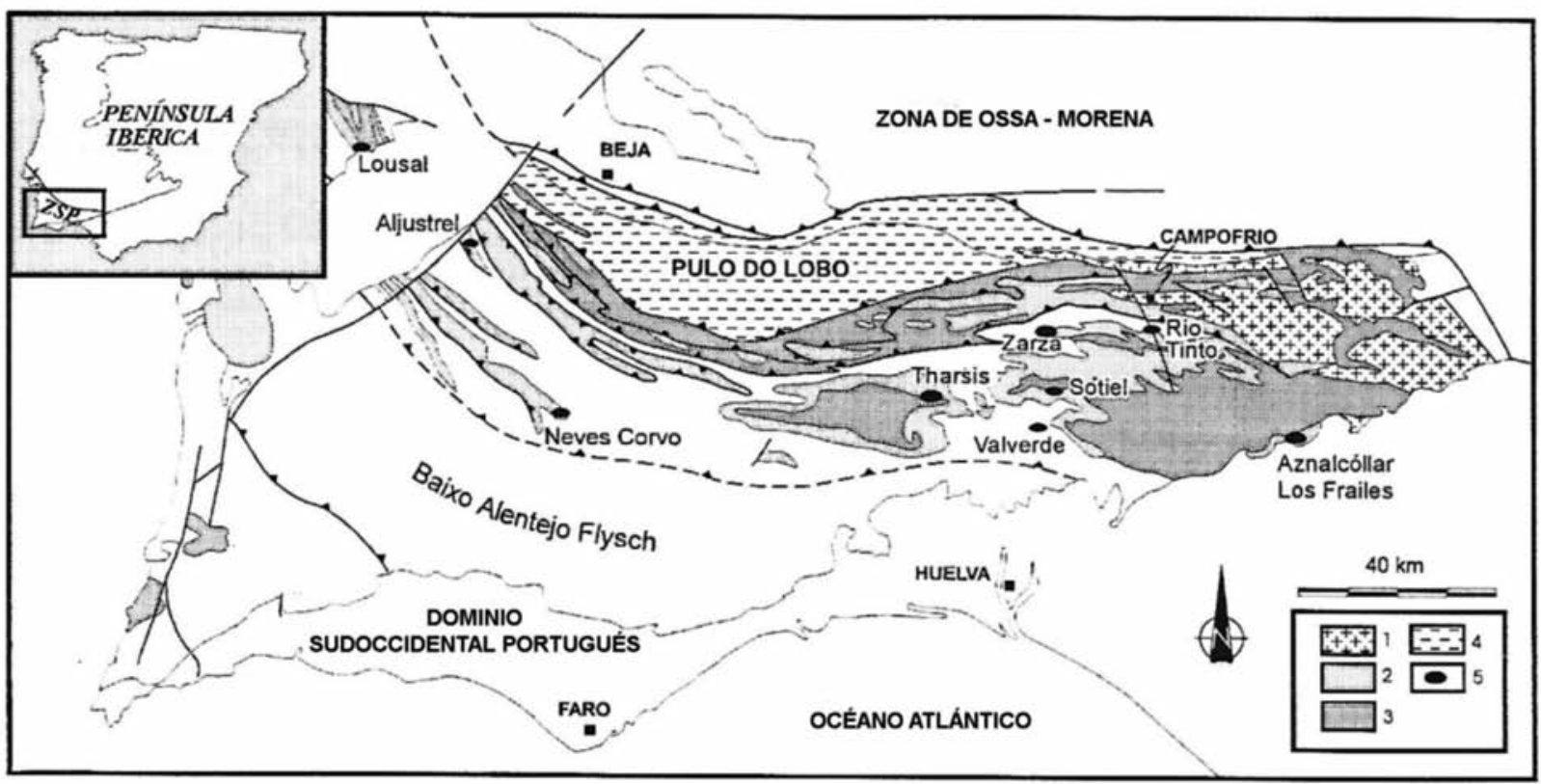

Figura 2. Encuadre geológico de la Faja Pirítica Ibérica (modificado de Leiste et al., 1998).

Figure 2. Geological context of the Iberian Pyritic Belt (modified from Leiste et al, 1998).

ciones, intercalados y gradados, con alternancias mineralógicas y texturales, entre masivas, bandeadas, en stockwork o diseminadas.

Así, se establecen (Ruiz de Almodovar and Saez, 1992; Leistel et al., 1998 y Velasco Roldan, 2014):

- Mineral pirítico, con los siguientes contenidos medios en metales básicos: $\mathrm{Cu} 0,7 \%, \mathrm{~Pb} \mathrm{0,8 \%} \mathrm{y}$ Zn $1,3 \%$ y contenidos en Au bajos, en torno a 0,3 $\mathrm{g} / \mathrm{t}$ y $\mathrm{Ag} 33 \mathrm{~g} / \mathrm{t}$. Aparece tanto con estructuras masivas como diseminadas y en stockwork. Las mineralizaciones piríticas masivas son las más comunes y constituyen el grueso de los recursos en los grandes yacimientos.

- Mineral complejo polimetálico, con contenidos

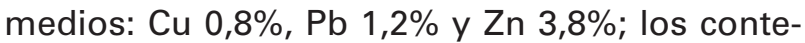
nidos en Au oscilan entre 0,5 g/t y $1 \mathrm{~g} / \mathrm{t}$ y los de Ag entre 55 y $60 \mathrm{~g} / \mathrm{t}$. Puede presentarse con estructuras masivas, bandeadas o diseminadas. Predominan en los depósitos de la banda norte de la Faja.

- Mineral cobrizo, con valores medios: $\mathrm{Cu} 2,1 \%$, $\mathrm{Pb} 0,18 \%$ y $\mathrm{Zn} 0,65 \%$. Suele aparecer en los sectores centrales y en el muro de los yacimientos masivos, con estructuras bandeadas, masivas, diseminadas o en stockwork. Los contenidos en Au oscilan entre $0,2 \mathrm{~g} / \mathrm{t}$ y $1 \mathrm{~g} / \mathrm{t}$, con algún valor errático entre $2 \mathrm{~g} / \mathrm{t}$ y $4 \mathrm{~g} / \mathrm{t}$. La facies cobriza puede alcanzar contenidos en $\mathrm{Cu}$ con la categoría de anómalos a escala de yacimiento, como es el caso de Neves Corvo en el sector portugués de la FPI.

Aparte de estos tipos de mineralizaciones de amplia distribución, se describen otras dos, de carácter más local, por el interés que presentan sus contenidos en Au. (Strauss and Beck, 1990).

- Mineral silicatado, facies con carácter local descrita en el yacimiento de La Zarza (valores medios $\mathrm{Cu} 2,1 \%$, $\mathrm{Pb} 0,8 \%$ y $\mathrm{Zn} \mathrm{1,8 \% ).} \mathrm{Aparece} \mathrm{en}$ el tránsito entre el stockwork y el depósito masivo, con estructura bandeada o masiva en una matriz silícea autobrechificada. Contenido medio en $\mathrm{Au} 1,17 \mathrm{~g} / \mathrm{t}$ y en $\mathrm{Ag} 35 \mathrm{~g} / \mathrm{t}$.

- Mineral carbonatado, en Filón Norte de Tharsis. Aparece en el techo y en los márgenes de la masa mineralizada, con estructura brechoide de clastos de pirita masiva redepositada en una matriz carbonatada (ankerita -siderita) y silícea. Contenido medio en Au 1,67 g/t y en Ag 16 g/t.

Como se observa, los contenidos medios en Au de estas mineralizaciones primarias no son llamativos, aunque como ya se ha indicado en varios yacimientos, del sector español de la FPI, existen zonas en las que se superan las $2 \mathrm{~g} / \mathrm{t}$ de Au: La Zarza (mineral bandeado 5,11 g/t), Lomero Poyatos (polimetálico $4 \mathrm{~g} / \mathrm{t}$ ), San Platón (minerales complejo y pirítico $2,05 \mathrm{~g} / \mathrm{t}$ ) y Filón Norte de Tharsis (stockwork 2,76 g/t).

Un capítulo aparte es el de las mineralizaciones secundarias, producto de las alteraciones supergéni- 
cas de los yacimientos aflorantes. Esencialmente constituidas por monteras ferruginosas, o gossan, y zonas de cementación, con enriquecimientos en Au$\mathrm{Ag}$ y $\mathrm{Cu}$ respectivamente. En estos yacimientos, y en alguno más, las monteras limonitizadas presentan enriquecimientos en Au-Ag notables, de tal modo que durante un periodo largo de tiempo han constituido el principal objetivo de la exploración y explotación para los metales preciosos de la FPI. Actualmente se pueden considerar como unos recursos prácticamente agotados, exceptuados nuevos hallazgos bajo la cobertera terciaria.

\section{Mineralogía del oro en la FPI}

La mineralogía del Au presenta fuertes diferencias entre yacimientos, e incluso dentro de un mismo depósito. Los trabajos de Marcoux et al. (1996) y Leistel et al. (1998) plantean para el Au contenido en los sulfuros masivos, del sector español de la FPI, dos asociaciones mineralógicas distribuidas geográficamente: en la zona sur, el tipo Tharsis-Sotiel-Migollas, en el que $\mathrm{Au}+\mathrm{Co} \pm \mathrm{Bi} \pm \mathrm{Cu}$ fundamentalmente aparece en los stockworks y en el enraizamiento de los depósitos y el tipo Río Tinto-Aznalcóllar-La Zarza, más al norte, en el que $A u+Z n+A g \pm A s \pm T l \pm H g$ se presenta en las facies de sulfuros polimetálicos, a muro o en posición distal. No obstante, tanto al sur como al norte, existen algunas mineralizaciones de sulfuros con $\mathrm{Au}$ que no se adaptan a esta distribución.

Predominan, sobre el oro nativo, el electrum, con más del $20 \%$ de $\mathrm{Ag}$, y las aleaciones con $\mathrm{Ag} \mathrm{y} \mathrm{Hg}$, oscilando éste último entre $0,2 \%$ y $24 \%$. En general se trata de cristales subidiomorfos, de tamaños inferiores a $20 \mu \mathrm{m}$, con purezas muy variables, oscilando entre 898 y 362 milésimas. De forma simplificada, se pueden establecer dos grupos: minerales de pureza elevada, en las facies silicatadas y en algunos stockworks, asociados a paragénesis de $\mathrm{Cu}$ y $\mathrm{Co}-\mathrm{Bi}$, y electrum y otras aleaciones, con $\mathrm{Hg}$ y $\mathrm{Ag}$, asociados a sulfuros polimetálicos y a facies de removilización hidrotermal. El oro secundario, de los gossans, suele presentarse en partículas de aleaciones $\mathrm{Au}-\mathrm{Ag}$ y $\mathrm{Au}-$ $\mathrm{Ag}-\mathrm{Hg}$, con formas muy irregulares y tamaños inferiores a $40 \mu \mathrm{m}$. (Velasco Roldan, 2014).

\section{Producción de oro en la Faja Pirítica Ibérica}

La producción tradicional del oro, en la Faja Pirítica, ha procedido de la explotación de las monteras limoníticas, de las que actualmente quedan muy pocos recursos sin tratar, y en menor medida, hasta 1990, de la cáscara de cobre (IGME, 2014). Otra mena importante para la recuperación del oro, como coproducto, han sido las cenizas de tostación de los minerales piríticos, pero este recurso, una vez que ha cesado la producción de ácido sulfúrico, también está en vías de agotamiento. Una parte del oro contenido en los polimetálicos es un coproducto que habitualmente se recupera en los concentrados piríticos de desbaste y rechazo, y el resto en las etapas finales de la metalurgia.

La Figura 3 recoge los datos de la producción española de oro primario entre 1990 y 2014 y refleja la significación que ha tenido la minería del gossan de la Faja Pirítica frente a la del oro/cobre del Noroeste.

En los últimos 40 años se ha dedicado un gran esfuerzo en investigación aplicada para el beneficio de los sulfuros complejos de la Faja Pirítica, aunque con resultados no demasiado alentadores. En los diversos procesos diseñados siempre se tuvo en cuenta la recuperación de los metales preciosos y en el caso de los esquemas de flotación, global, diferencial o semidiferencial, la gestión de los estériles piríticos, portadores de la mayor parte del oro (J.L. Álvarez-Marcos, 1996).

En los últimos tiempos se observan movimientos especulativos para tratar de conseguir nuevos derechos mineros, con la clasificación de yacimiento de origen no natural (recurso de la Sección B en la vigente Ley de Minas) para los escasos vacíes de cenizas de pirita que aún quedan e incluso para los estériles de la flotación de los minerales polimetálicos y del tratamiento de gossans. Evidentemente, el principal elemento que mueve al interés por estos acopios es el oro.

Estos materiales ya han pasado la etapa de reducción de tamaño, que es la parte más costosa del beneficio de los minerales, y, para poder procesarlos, se requiere un pretratamiento que, básicamente, comporta la flotación de la pirita, su posterior oxidación y, finalmente, un proceso de cianuración para poder extraer los metales preciosos.

Si bien es cierto que los costes de tratamiento se elevan a medida de su complejidad, en periodos de alza de la cotización del metal estos costes pueden llegar a ser cubiertos $y$, por otra parte, la reutilización de esos materiales, con las técnicas más eficientes y respetuosas del medio, contribuiría a mejorar la calidad medioambiental de las zonas de impactos previos.

No obstante, aun estando prácticamente agotados los recursos tradicionales, que contenían las leyes más productivas, y habida cuenta de los importantes volúmenes de recursos de pirita y metales básicos, el potencial en metales preciosos de la FPI continúa 


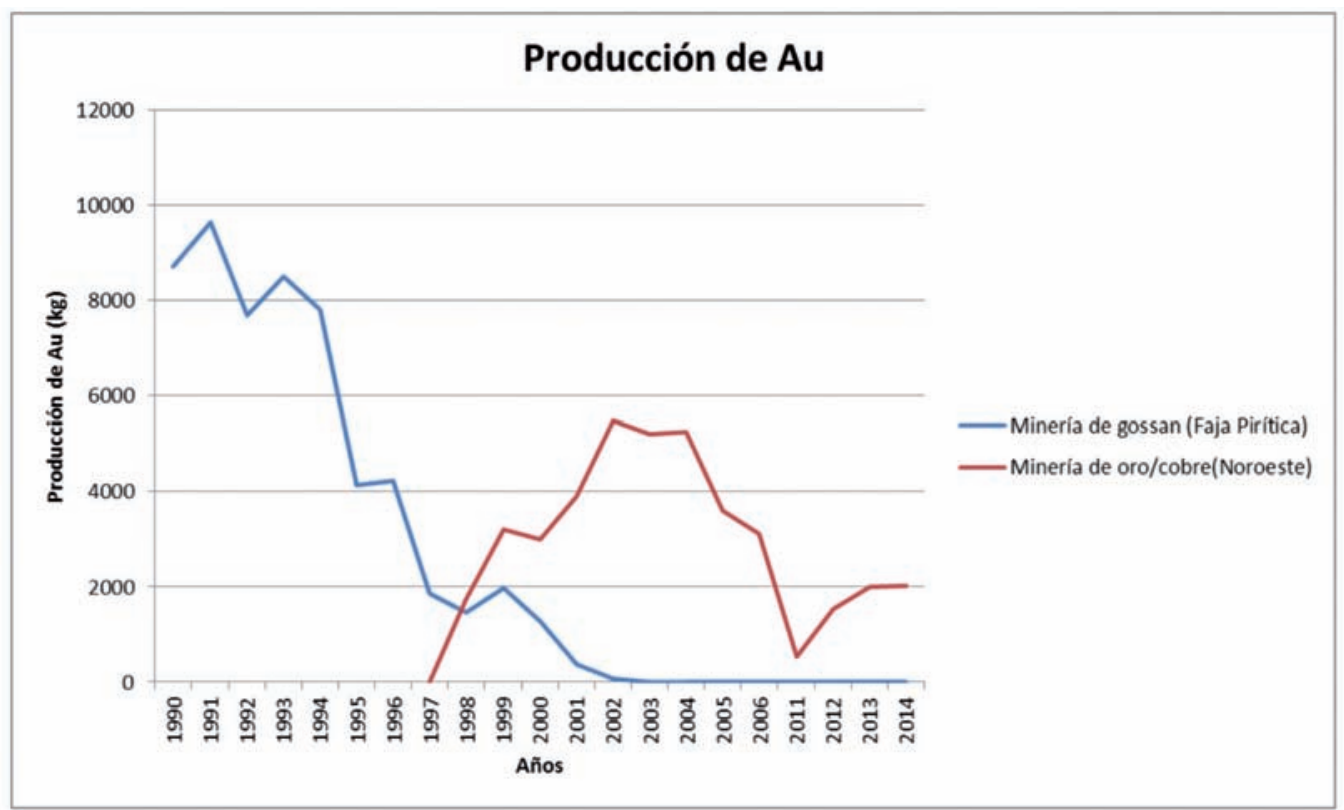

Figura 3. Datos de producción española de oro primario entre 1990 y 2014.

Figure 3. Spanish production of primary gold from 1990 to 2014.

siendo considerable, aunque se trate de mineralizaciones con contenidos bajos en Au-Ag.

Los nuevos proyectos metalúrgicos para el beneficio del oro se están orientando al tratamiento de las menas presentes en los tipos de mineralizaciones primarias, que previamente se han descrito.

\section{Tratamiento de minerales de oro}

Para lograr una extracción eficiente del oro, como para cualquier otra sustancia, es necesario un estricto control del proceso y para ello es imprescindible, ante todo, conocer las características de las menas que van a ser procesadas y en función de ello elegir el proceso más adecuado, lo que exige el conocimiento de las propiedades del oro, las características físico-químico-mineralógicas de las menas que conforman el depósito, así como la comprensión de cómo inciden estos factores en el procesamiento de dichas menas. Aunque en general, se puede señalar que las propiedades físicas y químicas del oro pueden determinar métodos de procesamiento el rendimiento de éstos está íntimamente ligado y condicionado por su mineralogía. Así pues, las características paragenéticas, estructurales y texturales de un depósito mineral, así como la composición del encajante, determinan de forma rigurosa la caracterización mineralógica de un depósito mineral, $y$, por tanto, determina de forma general $y$, entre otras cosas, el método de beneficio (procesamiento) y, en particular, el rendimiento de todos los procesos químicos involucrados en la extracción de oro. Marsden and House, en 2006, establecen los siguientes factores a considerar previamente al diseño de un proceso completo de tratamiento.

- Minerales con los que se presenta el oro

- Distribución de tamaños de granos de oro

- Mineralogía de la ganga y de la roca encajante

- Asociaciones minerales

- Alteraciones minerales

- Variaciones de las anteriores dentro del depósito o en el tiempo.

El tratamiento de los minerales de oro se basa fundamentalmente en las propiedades del oro, su alto peso específico, su carácter hidrofóbico y su solubilidad en disoluciones cianuradas $u$ otros agentes acomplejantes, dando lugar a varios esquemas de tratamiento metalúrgico para recuperar el oro (Adams, 2005).

La industria moderna del oro utiliza principalmente cianuro de sodio, como agente acomplejante, el llamado método de cianuración (Udupa et al. 1990), debido a su alta eficacia en la disolución de oro, fácil obtención y bajo costo. A pesar de su alta toxicidad, es un reactivo que puede ser utilizado con seguridad y bajo riesgo para la salud y el medio ambiente.

El cianuro de sodio al disolverse en agua se ioniza y forma el ion cianuro donde, en condiciones ligeramente oxidantes, se coordina con el oro por medio de 
un intercambio electrónico. La reacción generalmente aceptada para representar la disolución del oro es la siguiente:

$$
4 \mathrm{Au}+8 \mathrm{NaCN}+\mathrm{O}_{2}+2 \mathrm{H}_{2} \mathrm{O} \rightarrow 4 \mathrm{NaAu}(\mathrm{CN})_{2}+4 \mathrm{NaOH}
$$

La disolución resultante se denomina "disolución cargada". El oro disuelto como complejo cianurado, denominado aurocianuro, en esta disolución se recupera precipitándolo con polvo de cinc o bien, mediante la adsorción con carbón activado, extrayéndolo de la disolución.

En el primer caso, el cinc sustituye al oro en el compuesto soluble aurocianuro, quedando disuelto y precipitando el oro. Posteriormente, el precipitado se filtra, calcina y funde para obtener el oro en lingotes (bullón).

Al reducirse los iones de oro se oxida el cinc y se forma tetracianuro de cinc, según las siguientes reacciones:

$$
\begin{gathered}
\mathrm{Au}(\mathrm{CN})_{2}^{-}+e \rightarrow \mathrm{Au}+2 \mathrm{CN}^{-} \\
\mathrm{Zn}+4 \mathrm{CN} \rightarrow \mathrm{Zn}(\mathrm{CN})_{4}^{2-}+2 e^{-} \\
2 \mathrm{Au}(\mathrm{CN})_{2}^{-}+\mathrm{Zn} \rightarrow \mathrm{Zn}(\mathrm{CN})_{4}^{2-}+2 \mathrm{Au}
\end{gathered}
$$

En cuanto a la adsorción mediante carbón activado, puede realizarse en tres formas:

- Carbón en pulpa (CIP): Primero se cianura y posteriormente, en otros tanques, se adsorbe el aurocianuro sobre el carbón.

- Carbón en lixiviación (CIL): La disolución con cianuro y la adsorción con carbón activo tiene lugar al mismo tiempo y en los mismos tanques.

- Carbón en lixiviación con oxígeno: Igual que el anterior, pero introduciendo además oxígeno para mejorar las condiciones lixiviantes del cianuro.

El proceso de lixiviación por cianuración no siempre es posible aplicarlo con éxito, de una manera directa, si no se tienen en cuenta las características del mineral. Para una lixiviación eficiente, el oro debe de encontrarse libre, en tamaños finos de partículas puras dentro del mineral, que no contengan impurezas que consuman el agente lixiviante o impidan la reacción de lixiviación.

Generalmente, solo se cianuran los minerales situados en la zona de oxidación donde la mayoría de los sulfuros han sido convertidos a compuestos oxidados. Cuando los minerales de oro están ligados a sulfuros de plomo, cobre y zinc, la práctica general es aplicar un tratamiento de flotación y, posteriormente, recuperar el oro en la afinación de los metales impuros obtenidos en la fundición donde se tratan los concentrados.
En el caso de minerales que están en la zona de cementación, es decir que contienen sulfuros y óxidos, a menudo se tratan primero por flotación para recuperar los sulfuros y posteriormente se cianuran las colas de flotación.

La necesidad de tratar menas refractarias ha generado el desarrollo y aplicación de nuevas técnicas que permitan mejorar la extracción del oro en este tipo de menas. Dichas técnicas de una u otra manera facilitan la conversión de los compuestos presentes que acompañan al oro en las especies refractarias, de manera que faciliten la liberación de las partículas metálicas de oro, para luego entrar en contacto íntimo con la disolución cianurada.

Por la dificultad, ya sea química o física, de extraer el oro en los minerales refractarios, se requiere de un tratamiento previo de oxidación (pretratamiento) para liberar el oro encapsulado en estos minerales y permitir así su contacto directo con el reactivo de lixiviación. En las últimas décadas se han realizado grandes esfuerzos en el tratamiento de minerales que no era posible someter a un proceso de cianuración sin alguna forma de tratamiento previo. El pretratamiento de las Ilamadas menas refractarias está generalmente orientado a la liberación del oro encapsulado en sulfuros minerales (Demopoulus and Papangelakis, 1989).

Los métodos disponibles para la oxidación se pueden dividir en dos categorías:

- Procesos pirometalúrgicos

- Procesos hidrometalúrgicos

Los procesos pirometalúrgicos de sulfuros $y$ menas carbonatadas han sido empleados, y completamente probados, en el mundo durante décadas (Fleming, 1992), sin embargo, estos procesos son muy contaminantes principalmente por las emisiones de dióxido de azufre. Como consecuencia de las políticas medioambientales existentes y de la necesidad de reducir los elevados costes de inversión y operación, en las últimas décadas han ganado terreno los procesos de oxidación hidrometalúrgica, como alternativa más eficiente a los procesos de tostación para el tratamiento contra la refractariedad y asimismo como respuesta a las crecientes cotizaciones del metal que han ofrecido la oportunidad de explotar depósitos minerales refractarios, cuyos contenidos y mineralogías no los hacían, hasta entonces, económicamente rentables.

\section{Oxidación pirometalúrgica}

La tostación es uno de los métodos tradicionales para el tratamiento de minerales refractarios de oro. El 
objetivo de la tostación es oxidar los sulfuros a óxidos o a sulfatos. La tostación es una operación relativamente costosa, solo aplicable a minerales de alta ley $(>3 \mathrm{~g} / \mathrm{t})$. Mediante el proceso de tostación, un mineral, o concentrado, se lleva a una determinada temperatura y bajo condiciones tales que, sin llegar a la fusión de los constituyentes, ocurra una transformación química de los componentes respecto a su estado inicial, haciéndolos más susceptibles a los tratamientos posteriores de extracción por cianuración (Hong Yon Sohn and Rajendra, 1979; Van Lierde, 2002).

La tostación puede llevarse a cabo en procesos de una sola etapa o en dos etapas, dependiendo del tipo de mineral. El proceso de una sola etapa consiste en una tostación directa del mineral en una atmósfera oxidante. El proceso de dos etapas emplea, en la primera de ellas, condiciones reductoras, originando un producto intermedio poroso que en la segunda etapa se trata en atmosfera oxidante para completar la oxidación. El objetivo es producir una calcina porosa de óxidos de hierro para facilitar el mejor contacto con el agente lixiviante del oro.

La tostación de minerales refractarios permite romper el encapsulamiento del oro en minerales de tipo pirita y arsenopirita, pues transforma los sulfuros en óxidos de gran porosidad. Mediante el proceso de tostación, los cambios químicos y mineralógicos que sufre la pirita y la arsenopirita son los siguientes:

Tostación de la pirita: En condiciones oxidantes, la pirita se oxida a $\mathrm{Fe}_{2} \mathrm{O}_{3}$ (Norwood, 1939):

$$
4 \mathrm{FeS}_{2}+11 \mathrm{O}_{2} \rightarrow 2 \mathrm{Fe}_{2} \mathrm{O}_{3}+8 \mathrm{SO}_{2}
$$

En condiciones reductoras, la pirita se descompone en pirrotina y azufre.

$$
\mathrm{FeS}_{2} \rightarrow \mathrm{FeS}+\mathrm{S}(\mathrm{g})
$$

El azufre volatilizado se oxida a dióxido de azufre en presencia de oxígeno:

$$
\mathrm{S}(\mathrm{g})+\mathrm{O}_{2} \rightarrow \mathrm{SO}_{2}
$$

Tostación de la arsenopirita: Bajo condiciones reductoras, la arsenopirita se descompone en pirrotina y arsénico:

$$
\begin{gathered}
\mathrm{FeAsS}(\mathrm{s}) \rightarrow \mathrm{FeS}(\mathrm{s})+\mathrm{As}(\mathrm{g}) \\
2 \mathrm{As}(\mathrm{g})+3 / 2 \mathrm{O}_{2}(\mathrm{~g}) \rightarrow \mathrm{As}_{2} \mathrm{O}_{3}(\mathrm{~g})
\end{gathered}
$$

En la segunda etapa de tostación, se aumenta la temperatura y el consumo de oxígeno para formar $\mathrm{As}_{2} \mathrm{O}_{3}$ y completar la conversión de sulfuros a óxidos.

En el proceso de tostación se producen $\mathrm{SO}_{2}$ y un producto poroso (calcina) que puede tratarse por lixiviación. Sin embargo, esta práctica crea problemas ambientales ya que los gases de la tostación, además del $\mathrm{SO}_{2}$, contienen arsénico, antimonio, azufre y/o mercurio. Aunque existen nuevas técnicas para el control del impacto ambiental, éstas son muy costosas. En definitiva, pese a que la oxidación térmica es el proceso más conocido y efectivo técnicamente, su uso es muy restrictivo por los altos costos de producción y contaminación ambiental.

\section{Oxidación hidrometalúrgica}

En los procesos hidrometalúrgicos de oxidación, la mayoría de los desarrollos en el pretratamiento de minerales de oro refractario se han dado, básicamente, en tres áreas: en la oxidación a presión atmosférica en medio ácido o alcalino, en la oxidación biológica y en la oxidación a presión y a elevadas temperaturas, también en medio ácido o alcalino.

La lixiviación directa, de menas o concentrados de sulfuros metálicos, es un proceso químico de disolución mediante el cual, en presencia de un agente oxidante adecuado, los sulfuros metálicos se disuelven en ácidos minerales para proporcionar una disolución de sales metálicas y azufre elemental; siendo el factor determinante del proceso la cinética de la reacción entre los diferentes sulfuros y el agente, o agentes, lixiviantes seleccionados (ITGE, 1994).

Los procesos de lixiviación pueden llevarse a cabo a presión en autoclaves, en presencia de oxígeno y a temperaturas elevadas, o bien a presión atmosférica y temperaturas inferiores a $100^{\circ} \mathrm{C}$.

\section{Oxidación a presión}

Los minerales refractarios de oro pueden descomponerse con rapidez a temperaturas y presiones elevadas, usando oxígeno como agente oxidante. Las reacciones tienen lugar en reactores de presión, conocidos como autoclaves, que son capaces de resistir las altas temperaturas y presiones requeridas. La oxidación a presión es uno de los procesos hidrometalurgicos de pretratamiento que actúan por destrucción química de los minerales que encapsulan al oro y/o por la descomposición de componentes nocivos del mineral. La oxidación a presión se lleva a cabo a temperaturas que oscilan entre 170 y $225^{\circ} \mathrm{C}$, presiones totales de 1.100 a $3.200 \mathrm{kPa}$ y presión parcial de oxígeno de 350 a $700 \mathrm{kPa}$, alcanzándose la oxidación completa de los sulfuros de oro en 1 a 3 horas (Berezowshi et al, 1991). 
Este procedimiento se puede llevar a cabo tanto en medio alcalino como en medio ácido, siendo este último el más desarrollado para aplicaciones comerciales. Mediante este procedimiento se consigue la oxidación completa de la pirita y arsenopirita a sulfatos y arseniatos, con una mínima formación de azufre elemental. Este último elemento es indeseable, ya que incrementa el consumo de reactivos en la siguiente etapa de cianuración.

Las principales reacciones que tienen lugar en la oxidación de la pirita en medio ácido son las siguientes:

$$
\begin{gathered}
2 \mathrm{FeS}_{2}+7 \mathrm{O}_{2}+2 \mathrm{H}_{2} \mathrm{O} \rightarrow 2 \mathrm{FeSO}_{4}+2 \mathrm{H}_{2} \mathrm{SO}_{4} \\
4 \mathrm{FeSO}_{4}+\mathrm{O}_{2}+2 \mathrm{H}_{2} \mathrm{SO}_{4} \rightarrow 2 \mathrm{Fe}_{2}\left(\mathrm{SO}_{4}\right)_{3}+2 \mathrm{H}_{2} \mathrm{O}
\end{gathered}
$$

Parte del sulfato férrico formado puede hidrolizarse y precipitar según las siguientes reacciones:

$$
\begin{gathered}
\mathrm{Fe}_{2}\left(\mathrm{SO}_{4}\right)_{3}+3 \mathrm{H}_{2} \mathrm{O} \rightarrow \mathrm{Fe}_{2} \mathrm{O}_{3}+3 \mathrm{H}_{2} \mathrm{SO}_{4} \\
\mathrm{Fe}_{2}\left(\mathrm{SO}_{4}\right)_{3}+2 \mathrm{H}_{2} \mathrm{O} \rightarrow 2 \mathrm{Fe}(\mathrm{OH}) \mathrm{SO}_{4}+\mathrm{H}_{2} \mathrm{SO}_{4} \\
3 \mathrm{Fe}_{2}\left(\mathrm{SO}_{4}\right)_{3}+14 \mathrm{H}_{2} \mathrm{O} \rightarrow 2 \mathrm{H}_{3} \mathrm{OFe}_{3}\left(\mathrm{SO}_{4}\right)_{2}+5 \mathrm{H}_{2} \mathrm{SO}_{4}
\end{gathered}
$$

La arsenopirita se oxida de acuerdo a la siguiente reacción:

$$
4 \mathrm{FeAsS}+11 \mathrm{O}_{2}+2 \mathrm{H}_{2} \mathrm{O} \rightarrow 2 \mathrm{AsO}_{2}+4 \mathrm{FeSO}_{4}
$$

La oxidación de los sulfuros refractarios tiene lugar a temperaturas superiores a $170^{\circ} \mathrm{C}$, con objeto de oxidar completamente los sulfuros a la forma sulfato y oxidar cualquier azufre elemental (Long and Dixon, 2004 and Papangelakis and Demopoulos, 1989) que se haya formado como producto intermedio:

$$
2 \mathrm{~S}^{\circ}+3 \mathrm{O}_{2}+2 \mathrm{H}_{2} \mathrm{O} \rightarrow 2 \mathrm{H}_{2} \mathrm{SO}_{4}
$$

En presencia de sodio o potasio, también es posible que el sulfato férrico se hidrolice y precipite como jarosita, $\left(\mathrm{KFe}_{3}\left(\mathrm{SO}_{4}\right)_{2}(\mathrm{OH})_{6}\right)$. Durante la oxidación ácida a presión, el oro no es atacado y permanece en el residuo siendo la disolución la que se desecha.

\section{Lixiviación química a presión atmosférica en medio sulfato}

En la lixiviación a presión atmosférica gran parte de los procesos conocidos tienen lugar en medio sulfato. El sulfato férrico presenta un amplio campo de aplicación como agente lixiviante en diversos procesos hidrometalúrgicos, aprovechando la fácil reducción de la sal férrica para provocar la oxidación de otros compuestos, pero, para conseguir un rendimiento alto, se necesita una concentración de iones férricos elevada.

Entre los principales factores que influyen en la lixiviación de los sulfuros metálicos podemos citar los siguientes:

- Mineralogía

- Granulometría

- Tiempo de lixiviación

- Concentración óptima de sulfato férrico en la etapa de lixiviación.

- Densidad óptima de pulpa en el circuito de lixiviación

- Temperatura óptima de operación en el circuito de lixiviación.

- Potencial redox durante la etapa de lixiviación

- pH óptimo de operación en la etapa de lixiviación, teniendo en cuenta su influencia en el cierre del circuito

La reacción global que tiene lugar es la siguiente:

$$
\mathrm{Fe}_{2}\left(\mathrm{SO}_{4}\right)_{3}+\mathrm{MeS} \rightarrow \mathrm{MeSO}_{4}+2 \mathrm{FeSO}_{4}+\mathrm{S}^{0}
$$

donde $\mathrm{Me}$ puede ser $\mathrm{Zn}, \mathrm{Cu}, \mathrm{Pb}, \mathrm{Fe}$, etc.

La lixiviación de un sulfuro metálico, desde el punto de vista electroquímico, involucra dos semireacciones, una semireacción de oxidación del sulfuro y una semireación de reducción del agente oxidante.

Para un sulfuro mineral cualquiera, $M e S$ en presencia de un oxidante catiónico $\mathrm{N}^{n+}$, se tiene que las reacciones involucradas son las siguientes:

Oxidación del mineral:

$$
M e S \rightarrow M e^{m+}+S^{o}+m e-(\text { anódica })
$$

Reducción del oxidante:

$$
N^{n+}+e^{-} \rightarrow N^{(n-1)+} \text { (catódica) }
$$

La suma de ambas semirreacciones da lugar a la reacción global anterior.

Durante la reacción el ion férrico $\left(\mathrm{Fe}^{3+}\right)$ se reduce a ion ferroso $\left(\mathrm{Fe}^{2+}\right)$, siendo necesario reoxidar este $\mathrm{Fe}^{2+}$ para su posterior recirculación en el proceso.

La oxidación de la forma ferrosa, $\mathrm{Fe}^{2+}$, presenta grandes dificultades de tipo económico al no haberse encontrado el agente barato que la provoque. Tras desechar, por razones económicas, la oxidación por agentes clásicos como el permanganato, agua oxigenada, oxígeno de gran pureza, etc., queda como único agente de interés el oxígeno del aire.

$$
2 \mathrm{FeSO}_{4}+\mathrm{H}_{2} \mathrm{SO}_{4}+1 / 2 \mathrm{O}_{2} \rightarrow \mathrm{Fe}_{2}\left(\mathrm{SO}_{4}\right)_{3}+\mathrm{H}_{2} \mathrm{O}
$$


En el caso de la FPI las principales especies mineralógicas a considerar en la lixiviación son las siguientes:

\section{Calcopirita:}

$$
\mathrm{CuFeS}_{2}+2 \mathrm{Fe}_{2}\left(\mathrm{SO}_{4}\right)_{3} \rightarrow \mathrm{CuSO}_{4}+5 \mathrm{FeSO}_{4}+2 \mathrm{~S}^{\circ}
$$

Blenda:

$$
\mathrm{ZnS}+\mathrm{Fe}_{2}\left(\mathrm{SO}_{4}\right)_{3} \rightarrow \mathrm{ZnSO}_{4}+2 \mathrm{FeSO}_{4}+\mathrm{S}^{\circ}
$$

Galena:

$$
\mathrm{PbS}+\mathrm{Fe}_{2}\left(\mathrm{SO}_{4}\right)_{3} \rightarrow \mathrm{PbSO}_{4}+2 \mathrm{FeSO}_{4}+\mathrm{S}^{\circ}
$$

Pirita:

$$
\mathrm{FeS}_{2}+7 \mathrm{Fe}_{2}\left(\mathrm{SO}_{4}\right)_{3}+8 \mathrm{H}_{2} \mathrm{O} \rightarrow 15 \mathrm{FeSO}_{4}+8 \mathrm{H}_{2} \mathrm{SO}_{4}
$$

Arsenopirita:

$$
\mathrm{FeAsS}+5 \mathrm{Fe}^{3+} \rightarrow 6 \mathrm{Fe}^{2+}+\mathrm{As}^{3+}+\mathrm{S}^{\circ}
$$

El residuo contenido en etapa de lixiviación contiene azufre elemental, plomo, plata y el oro que hubiese en el mineral inicial (excepto en la pirita) con lo que es posible la recuperación de estos metales.

\section{Lixiviación por bacterias (biolixiviación)}

La lixiviación bacteriana, biolixiviación, también conocida como biohidrometalurgia puede definirse como un proceso natural de disolución que resulta de la acción de un grupo de bacterias con capacidad para oxidar sulfuros metálicos, permitiendo la liberación del metal contenido en el mineral (Ballester, 2005). La biolixiviación emplea bacterias específicas para lixiviar, disolver o extraer un metal de valor (cobre, zinc, níquel, cobalto, etc.) contenido en el mineral. El producto final de la biolixiviación es una solución ácida que contiene el metal en forma soluble (Iglesias y Carranza, 1994).

Dentro de los microorganismos empleados en la biolixiviación destaca la bacteria Thiobacillus ferrooxidans, microorganismo mesófilo, que vive en condiciones ácidas y anaerobias. Presenta una actividad metabólica importante entre los 20 y los $40^{\circ} \mathrm{C}$ de temperatura.

La biolixiviación, como pretratamiento de menas auríferas refractarias en matriz de sulfuros, puede tener lugar a través de dos mecanismos distintos (Iglesias et al 1998): el mecanismo de contacto direc- to, que requiere un íntimo contacto físico entre la bacteria y el mineral a lixiviar, y el mecanismo de contacto indirecto en el que los sulfuros son oxidados por el ion férrico, agente lixiviante, que la bacteria genera.

El mecanismo indirecto considera que el único papel de las bacterias es la regeneración del agente lixiviante $\left(\mathrm{Fe}^{3+}\right)$, por lo que se separan las etapas químicas (lixiviación) y biológica del proceso (biooxidación).

A través de la etapa química de lixiviación, se generan iones ferrosos $\left(\mathrm{Fe}^{2+}\right)$ y azufre elemental $\left(\mathrm{S}^{\circ}\right)$. Finalmente, estas especies químicas son reoxidadas biológicamente regenerando el ion férrico $\left(\mathrm{Fe}^{3+}\right)$ con producción de ácido sulfúrico, según las siguientes reacciones:

\section{Etapa química}

$$
\mathrm{MeS}+2 \mathrm{Fe}^{3+} \rightarrow \mathrm{M}^{2+}+2 \mathrm{Fe}^{2+}+\mathrm{S}^{\circ}
$$

\section{Etapa biológica}

$$
\begin{gathered}
4 \mathrm{FeSO}_{4}+\mathrm{O}_{2}+2 \mathrm{H}_{2} \mathrm{SO}_{4} \rightarrow 2 \mathrm{Fe}_{2}\left(\mathrm{SO}_{4}\right)_{3}+2 \mathrm{H}_{2} \mathrm{O} \\
2 \mathrm{Fe}^{2+}+1 / 2 \mathrm{O}_{2}+2 \mathrm{H}^{+} \rightarrow 2 \mathrm{Fe}^{3+}+\mathrm{H} 2 \mathrm{O} \\
2 \mathrm{~S}^{\circ}+3 \mathrm{O}_{2}+2 \mathrm{H}_{2} \mathrm{O} \rightarrow 2 \mathrm{H}_{2} \mathrm{SO}_{4}
\end{gathered}
$$

La cinética de estas reacciones está condicionada por la temperatura. A temperatura ambiente son muy lentas $y$, sin embargo, a temperaturas moderadamente altas, incluso muy por debajo del punto de ebullición de la disolución, son considerablemente más rápidas. El carácter mesófilo de las bacterias normalmente empleadas impide el recurso del aumento de la temperatura para acelerar el proceso de lixiviación; no obstante, la separación física de los efectos químico y biológico permite efectivamente la utilización de este recurso.

La oxidación bacteriana del ion ferroso puede realizarse con dos tipos de dispositivos esencialmente distintos: el modelo de suspensión bacteriana y el de la película bacteriana soportada. Como sus propios nombres indican, en el primero de ellos las bacterias se encuentran dispersas en un medio líquido, agitado o no, en el segundo se encuentran fijas en una película formada por las propias bacterias y un cemento de unión constituido por sulfatos básicos de hierro. Dicha película se soporta, en general, sobre un sólido inerte.

Según el mecanismo de contacto directo, la bacteria ataca al sulfuro metálico de forma directa, mediante su adherencia a la superficie del mineral, y posterior oxidación enzimática de éste por el transporte de electrones desde la parte reducida del mineral al oxí- 
geno disuelto. La acción bacteriana es independiente de la presencia del ion férrico y sólo se requiere un íntimo contacto físico entre la bacteria y la superficie del mineral en condiciones anaerobias. Las bacterias precisan de oxígeno y $\mathrm{CO}_{2}$ para su crecimiento y para oxidar los minerales, se adaptan a valores de $\mathrm{pH}$ ácidos y su actividad es más eficiente a bajas temperaturas $\left(30^{\circ} \mathrm{C}\right.$ y $\left.40^{\circ} \mathrm{C}\right)$. La oxidación se da por reacciones químicas catalizadas enzimáticamente por la bacteria.

Considerando que la pirita es el sulfuro principal contenido en la mena, las reacciones que pueden tener lugar en el proceso de biolixiviación por contacto directo son las siguientes:

$$
\begin{gathered}
2 \mathrm{FeS}_{2}+7 \mathrm{O}_{2}+2 \mathrm{H}_{2} \mathrm{O} \rightarrow 2 \mathrm{FeSO}_{4}+2 \mathrm{H}_{2} \mathrm{SO}_{4} \\
4 \mathrm{FeSO}_{4}+\mathrm{O}_{2}+2 \mathrm{H}_{2} \mathrm{SO}_{4} \rightarrow 2 \mathrm{Fe}_{2}\left(\mathrm{SO}_{4}\right)_{3}+2 \mathrm{H}_{2} \mathrm{O} \\
\mathrm{FeS}_{2}+\mathrm{Fe}_{2}\left(\mathrm{SO}_{4}\right)_{3} \rightarrow 3 \mathrm{FeSO}_{4}+2 \mathrm{~S}^{\circ} \\
2 \mathrm{~S}^{\circ}+2 \mathrm{H}_{2} \mathrm{O}+3 \mathrm{O}_{2} \rightarrow 2 \mathrm{H}_{2} \mathrm{SO}_{4} \\
3 \mathrm{Fe}_{2}\left(\mathrm{SO}_{4}\right)_{3}+12 \mathrm{H}_{2} \mathrm{O} \rightarrow 2 \mathrm{HFe}_{3}\left(\mathrm{SO}_{4}\right)_{2}(\mathrm{OH})+5 \mathrm{H}_{2} \mathrm{SO}_{4}
\end{gathered}
$$

El principal inconveniente con el que tropieza la biolixiviación de menas metálicas sulfuradas, mediante el mecanismo de contacto directo, es la lenta cinética de este tipo de procesos que obliga a operar con tiempos de reacción muy elevados. Esto condiciona de forma notable el dispositivo industrial a emplear y, a su vez, el tipo de mineral a tratar.

Respecto al proceso de biolixiviación por mecanismos de contacto indirecto, las posibilidades de mejora cinética son mucho mayores a corto plazo. Solo es preciso separar los dos procesos que, de forma simultánea, tienen lugar en el reactor de lixiviación: el ataque químico al sulfuro metálico por parte del ion férrico y la oxidación bacteriana del ion ferroso producido. Basado en este mecanismo, podemos destacar el proceso desarrollado en la Universidad de Sevilla, conocido como proceso IBES (Indirect Bioleaching with Effects Separation) (Iglesias y Carranza, 1996). Otro proceso de iguales características es el proceso BRISA (Biolixiviación Rápida Indirecta con Separación de Acciones).

En cuanto al tratamiento de concentrados refractarios de oro, se han realizado numerosos esfuerzos durante los últimos años en la búsqueda de procesos comercialmente viables (Rodriguez et al, 2001), tales como el proceso BIOX (Van Aswegen, P.C. 1993.) y el proceso Bech Tech (Buddgen y Bunyard, 1994). El primero de ellos emplea reactores agitados, para degradar la matriz refractaria utilizando un cultivo mixto de bacterias mesófilas, en un rango de temperatura entre 40 y $45^{\circ} \mathrm{C}$. El proceso Bech Tech emplea igualmente reactores agitados utilizando bacterias termófilas moderadas.

\section{Otros procesos}

\section{Oxidación con ácido nítrico}

El uso del ácido nítrico como agente oxidante en el tratamiento de menas refractarias de pirita y arsenopirita, se ha venido investigando desde principios de los años 80. El ácido nítrico se disocia en medio acuoso y el ion nitrato producido es el agente oxidante que se involucra en varias reacciones de oxidación. En dichas reacciones también aparece el ion nitrito que, junto con el nitrato tienen la capacidad de oxidar a los sulfuros (Peters, 1992). Varios procesos han sido patentados, pero ninguno de ellos se ha aplicado comercialmente debido a la complejidad del pretratamiento y a los elevados costes: Procesos NITROX (Fair, K.J., et al, 1986), ARSENO (Beatti and Raudsepp, 1988) y REDOX (Beatti and Ismay, 1990).

\section{Oxidación con sales oxidantes (Proceso SEVERO)}

Este proceso, con sales oxidantes, en medio ácido, tiene como objetivo lixiviar mineral aurífero usando como medio lixiviante el ácido sulfúrico concentrado y adicionando sales oxidantes como el cloruro y el nitrato de sodio, logrando de esta forma que se produzca cloro y agua regia in situ, lixiviantes enérgicos para recuperar metales nobles como el oro, (Pardave and Beltrán, 2007)

\section{La I+d+i hidrometalúrgica en el IGME}

Parte de la labor de $I+D+i$ que el IGME ha llevado a cabo en el campo del beneficio de minerales, se ha centrado en la búsqueda de tratamientos alternativos de los sulfuros polimetálicos de la FPI, contemplando simultáneamente la recuperación del oro contenido en dichos sulfuros, así como la extracción de cualesquiera otros metales presentes susceptibles de beneficio económico, que contribuya a aminorar los costes de explotación. Para ello, se han combinado métodos de tratamientos tradicionales, como la cianuración, con otros de carácter innovador, como la lixiviación ácida a presión, la tostación oxidante, la lixiviación férrica a presión atmosférica y la biolixiviación.

Las líneas de innovación y desarrollo tecnológico en el tratamiento hidrometalúrgico de sulfuros complejos han ido dirigidas a la producción de metales no férreos, principalmente cobre y cinc de dichos sulfuros, basadas en procesos de lixiviación química y de biolixiviación. 
Los objetivos propuestos para estas actuaciones fueron los siguientes:

- Mayor aprovechamiento de los recursos minerales de la FPI

- Mejorar sensiblemente los sistemas productivos existentes

- Investigar y desarrollar las técnicas de extracción de metales por vía hidrometalúrgica

- Revitalizar la actividad minera

Durante el año 1994 se elaboró el proyecto "Estudio preliminar de recuperación del oro contenido en el mineral carbonatado de Tharsis", cuyo objetivo fue estudiar la recuperación de oro y los metales básicos. Para ello, se investigaron procesos alternativos de tratamiento a los de tostación para eliminar la refractariedad del oro mediante técnicas de lixiviación química y biológica. Inicialmente, estos procesos fueron realizados a escala de laboratorio, con objeto de estudiar el comportamiento de la muestra frente a técnicas metalúrgicas convencionales para el tratamiento de este tipo de menas.

En este sentido, se estudiaron los procesos de tostación, pirolisis, oxidación a presión, lixiviación férrica y procesos biohidrometalúrgicos. Después de cada uno de estos tratamientos los residuos obtenidos fueron sometidos a procesos de cianuración convencional. Los ensayos realizados sirvieron para evaluar los diferentes procesos de tratamiento y los inconvenientes y ventajas que presentaban cada uno de ellos, resaltando que la biolixiviación puede ser una alternativa de tratamiento para este tipo de mena carbonatada.

En el campo de la biolixiviación, se realizaron numerosos ensayos discontinuos (a escala "batch") sobre concentrados de cobre de diversas plantas en operación en la FPI, adquiriendo buenos conocimientos al producir cepas de bacterias termófilas y mesófilas bien adaptadas a las condiciones de ensayo, reduciendo paulatinamente los tiempos de disolución (IGME, 1994).

Durante los años 1995-1996 se estudió la viabilidad técnica del proceso biooxidativo en planta piloto del Au sobre muestras del stockwork de Tharsis (IGME, 1996). Los estudios realizados concluyeron que los procesos más adecuados de preconcentración, de elementos de interés (Au y Co), eran la flotación global de los sulfuros seguida de una biolixiviación del concentrado de flotación.

Los ensayos de biolixiviación en planta piloto se llevaron a cabo en un prototipo Biolift-Eimco, equipados con tres reactores de acero inoxidable de 60 litros de capacidad, con un doble sistema de agitación/aireación y recirculación de pulpa, diseñado para mezclar y airear pulpas de forma que se permita un adecuado desarrollo de la actividad microbiológica. Cada reactor está provisto de una camisa calorifugada que le permite alcanzar temperaturas de $30-35^{\circ} \mathrm{C}$, necesarias para el adecuado desarrollo de bacterias mesófilas.

En el año 1997, mediante un convenio suscrito con la Junta de Andalucía y la compañía Minas de Almagrera S.A. (MASA), el IGME estudió en planta piloto, en sus instalaciones de Tres Cantos (Madrid), la aplicación del proceso BRISA (Biolixiviación Indirecta con Separación de Acciones), Cuadro I, al tratamiento de concentrados de flotación de sulfuros metálicos no férreos de la Faja Pirítica, aplicando técnicas de biolixiviación. El objetivo de este proyecto fue estudiar la viabilidad técnica de la lixiviación férrica del cinc y cobre contenidos en un concentrado de cobre, procedente de la mina de Sotiel (masa Migollas) y la posterior regeneración del agente lixiviante mediante su recirculación a través de un biooxidador. Con este proceso se consigue una lixiviación de cobre y zinc, que se recuperarían por electrolisis previa purificación y acondicionamiento de la disolución.

El ensayo se llevó a cabo con una muestra de concentrado de $5000 \mathrm{~kg}$ procedente de la masa Migollas, de MASA. La capacidad de tratamiento de la planta piloto era de $10 \mathrm{~kg} / \mathrm{h}$, trabajando a una temperatura aproximada de $65^{\circ} \mathrm{C}$. Se alcanzó una lixiviación media de zinc del $80 \%$ y una lixiviación media de cobre del $90 \%$, con una oxidación media en el biooxidador de $4,33 \mathrm{~kg} \mathrm{de} \mathrm{Fe}^{2+} /$ hora. Los resultados de la recuperación obtenida cianurando el residuo, sin ningún tratamiento previo, fueron del $64,29 \%$ de oro y del $63,08 \%$ de plata (IGME, 1997).

La planta se estructuró en dos partes bien definidas: en la primera tenía lugar una lixiviación química y en la segunda una biooxidación. El circuito de lixiviación se componía de una lixiviación primaria y de una lixiviación catalítica. El empleo de una lixiviación primaria se hace necesario por la presencia de sulfuros secundarios de cobre, blenda y galena que acompañan a la calcopirita. En la etapa de biooxidación tiene lugar la regeneración del reactivo lixiviante, mediante bacterias mesófilas.

En el campo de la lixiviación química, en el año 2000, se formó una UTE constituida por el IGME, en colaboración con Nueva Tharsis S.A.L., Minas de Almagrera S.A. y Boliden-APIRSA, para investigar y desarrollar técnicas de extracción de metales por vía hidrometalúrgica utilizando el sulfato férrico como agente oxidante. Se recibió una subvención dentro del Programa de Fomento de la Investigación Técnica (PROFIT), incluido en el Plan Nacional de la Investigación Científica, Desarrollo e Innovación Tecnológica (2000-2003) del Programa Nacional de Diseño y Productividad Industrial. 


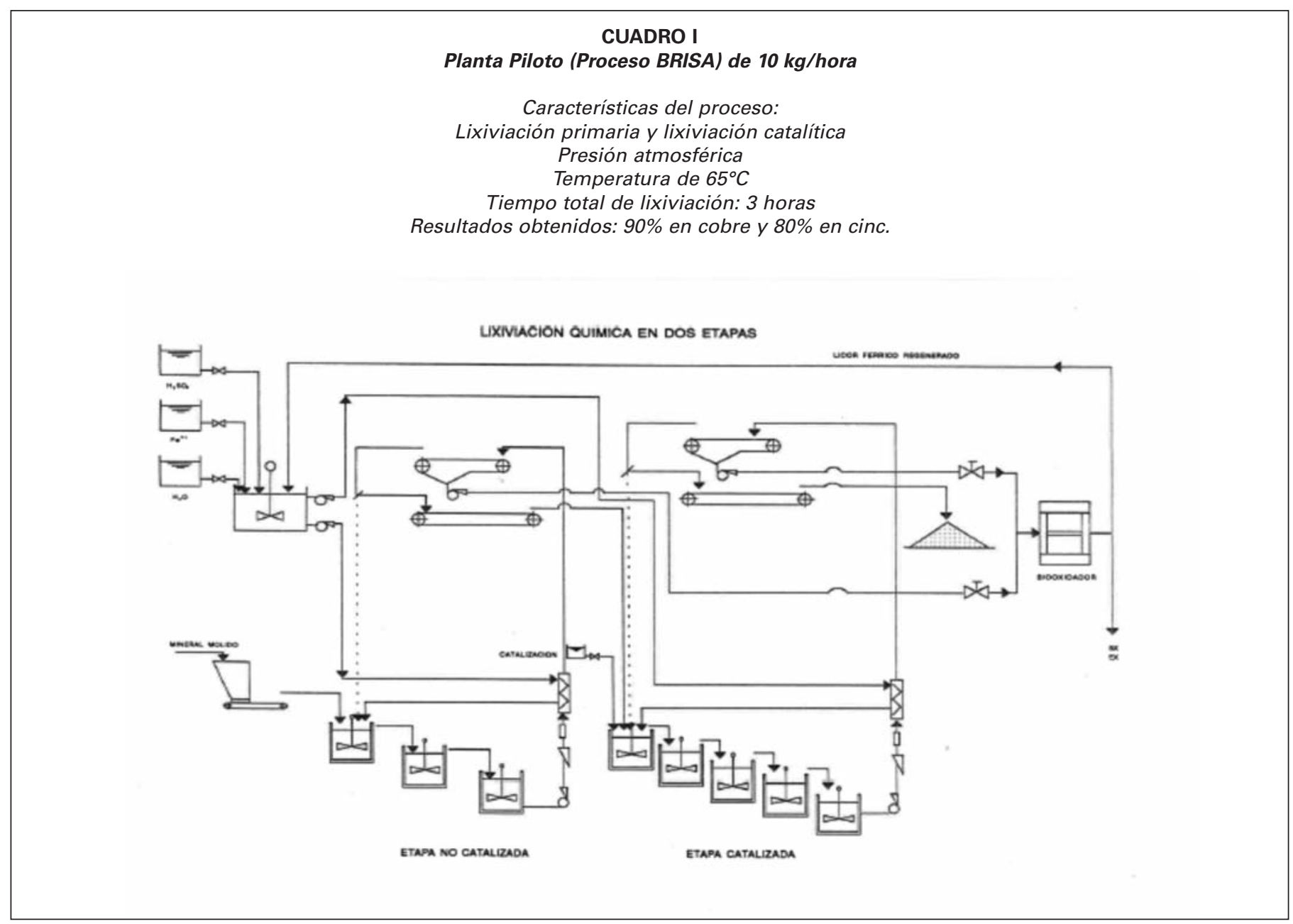

Con los resultados de los estudios previos llevados a cabo se diseñó, montó y operó una planta piloto a escala de laboratorio de lixiviación química con sulfato férrico, en las instalaciones de Nueva Tharsis S.A.L. (Huelva), para el aprovechamiento de los recursos minerales de la FPI, con una capacidad de tratamiento de 0,3-0,5 $\mathrm{kg}$ de concentrado/hora. La planta piloto funcionó ininterrumpidamente 24 horas/día, 5 días a la semana, tratando concentrados de $\mathrm{Cu}-\mathrm{Pb}-\mathrm{Zn}$ procedentes de Almagrera y Boliden-Apirsa.

En el año 2002, se construyó una nueva planta piloto de lixiviación en las instalaciones de Nueva Tharsis S.A.L., 10 veces mayor que la anterior, capaz de tratar 3-5 kg de concentrado cada hora, mejorada en muchos aspectos, al recoger toda la experiencia acumulada en la operación de la planta piloto anterior, y complementándola con las instalaciones de extracción por disolventes y electrolisis de cobre y zinc, para cerrar totalmente el circuito. Se obtuvieron resultados muy satisfactorios, puesto que se lograron lixiviaciones superiores al $79 \%$ del cobre y $98 \%$ del zinc. (IGME, 2003, 2004, 2006)

Durante el periodo 2006-2009, el IGME y la Junta de Andalucía, formalizaron nuevos convenios de colaboración, cuyo objetivo fue la realización de ensayos en la planta piloto, de mineral todo-uno directamente, es decir sin flotar, para confirmar los resultados obtenidos en discontinuo en laboratorio y determinar los parámetros necesarios para la evaluación y diseño de una planta industrial. Además, se pretendía con esta investigación, realizar las modificaciones necesarias en la planta piloto para adecuarla al tratamiento de minerales auríferos mediante la lixiviación férrica y recuperación posterior de metales preciosos, por cianuración o procesos alternativos.

Consecuencia de los resultados obtenidos durante estos 10 años de colaboración con la Junta de Andalucía, así como las investigaciones llevadas a cabo posteriormente en los laboratorios del IGME, mediante convenio de colaboración con la empresa 
Protón Ingenieros, se ha desarrollado un procedimiento hidrometalúrgico para el tratamiento de sulfuros complejos.

El procedimiento hidrometalúrgico tiene por finalidad un diseño de Planta Hidrometalúrgica para tratamiento de sulfuros complejos de cobre y cinc. La lixiviación de los sulfuros de cobre y zinc se realiza a presión atmosférica, en reactores abiertos, a una temperatura comprendida entre 80 y $100^{\circ} \mathrm{C}$. El método descrito permite el tratamiento directo de la mena, con bajas leyes en cobre y cinc, así como el tratamiento de concentrados globales de flotación. La lixiviación se lleva a cabo en una etapa, utilizando sulfato férrico como agente oxidante de los sulfuros. A diferencia de los procesos existentes, la regeneración del ion férrico tiene lugar en una etapa independiente de la lixiviación, utilizando aire atmosférico para aportar el oxígeno necesario para llevar a cabo la oxidación y manteniendo el pH a 4,0-5,5. En estas condiciones el ion férrico precipita en forma de hidróxido.

\section{CUADRO II}

Planta Piloto (Tharsis) de 10kg/hora

Características del proceso:

Lixiviación en una única etapa Presión atmosférica

Temperatura mayor de $90^{\circ} \mathrm{C}$

Tiempo total de lixiviación: 3 horas

Resultado obtenidos: $79 \%$ en cobre y $98 \%$ en cinc, obteniéndose ambos metales mediante extracción con disolventes y electrólisis.

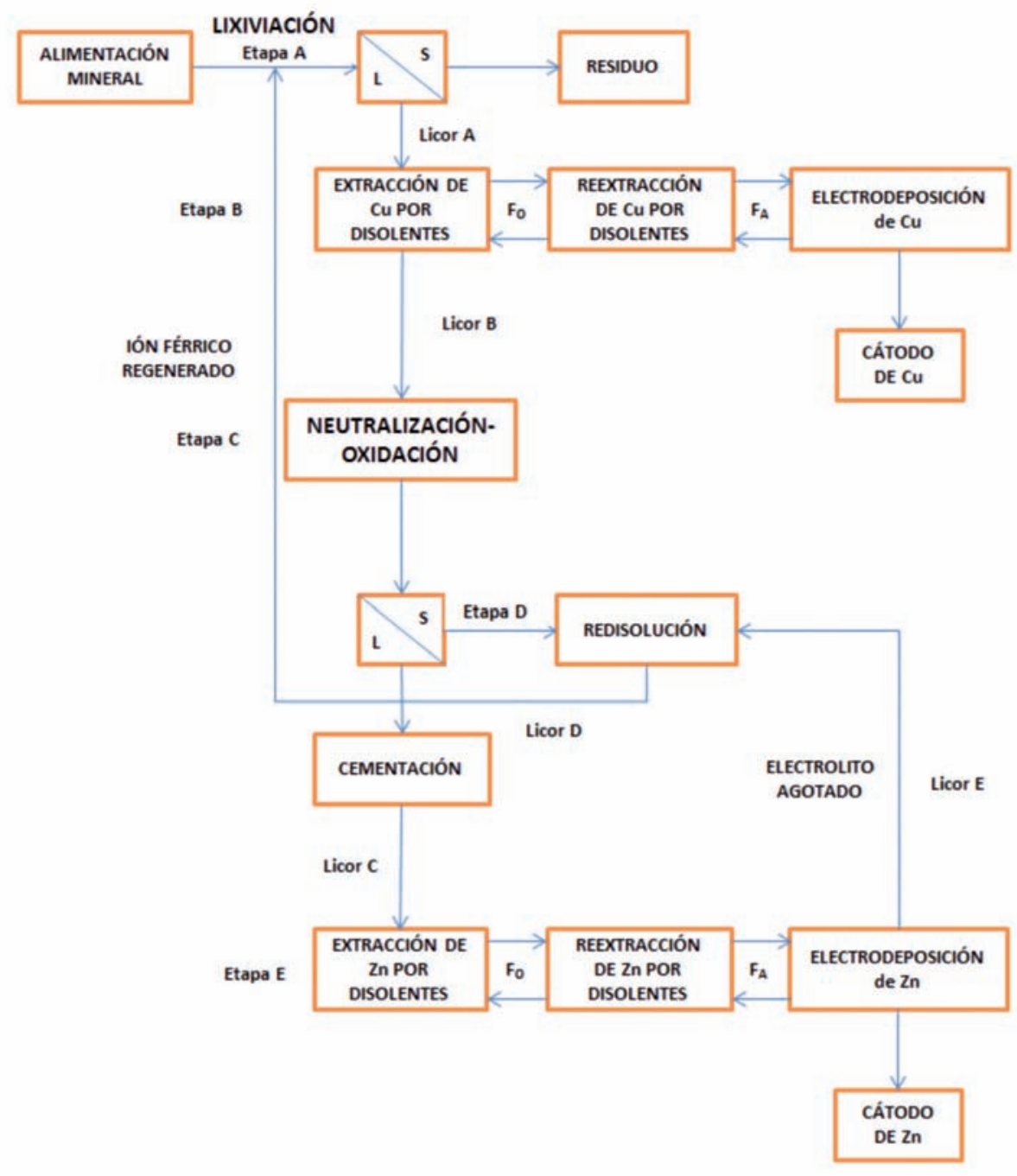


Esto supone una ventaja desde el punto de vista económico frente a otros procedimientos que utilizan oxígeno puro de gran pureza. Como agente neutralizante se pueden emplear diferentes bases. Entre ellas el amoniaco presenta una serie de ventajas ya que se puede adicionar a la disolución de manera continua y controlada, es un producto barato y asequible y no interfiere en la calidad del precipitado obtenido. Posteriormente se realiza la extracción por disolventes del cobre y cinc procedentes del licor para su tratamiento electrolítico. El Cuadro II muestra el diagrama de flujo del procedimiento de lixiviación directa de los sulfuros complejos de acuerdo con la invención.

En base a esta patente, el IGME y la empresa Protón Ingenieros han desarrollado, durante el periodo 2017-2018, una Planta Piloto de lixiviación de sulfuros de cobre y cinc. El Cuadro III, muestra el diagrama cualitativo de la Planta Piloto, así como sus principales parámetros de operación.

\section{Consideraciones Finales}

La Faja Pirítica Ibérica alberga, aun tras más de dos milenios de historia minera, un extraordinario poten- cial para el aprovechamiento de sus recursos de minerales metálicos. Pues bien, el aprovechamiento de ese potencial está directamente ligado a la capacidad de recuperar el oro contenido en los minerales refractarios; es decir, aquellos en los que no es suficientemente efectiva la cianuración convencional, ampliamente representados como sulfuros complejos en toda la Faja. La vía para conseguir incrementar la recuperación es llevar a cabo un pretratamiento de oxidación de los sulfuros, que permita lixiviar el oro y facilitar el contacto posterior con el cianuro como agente acomplejante, mejorando decisivamente la recuperación.

Existen varias opciones para llevar a cabo el pretratamiento de oxidación. Tradicionalmente se optó por la vía pirometalúrgica de la tostación para llevar a cabo la oxidación de piritas y arsenopirita, pero la aplicación de esta técnica conlleva la emisión de dióxido de azufre y metales pesados tóxicos, algo inaceptable desde el punto de vista medioambiental. Por este motivo, se están desarrollando distintos métodos hidrometalúrgicos, que permiten un control exhaustivo de los lixiviados y son respetuosos con el medioambiente. El pretratamiento hidrometalúrgico podría permitir en un futuro cercano el beneficio del oro contenido en el mineral primario de la FPI, pero también la recupera-

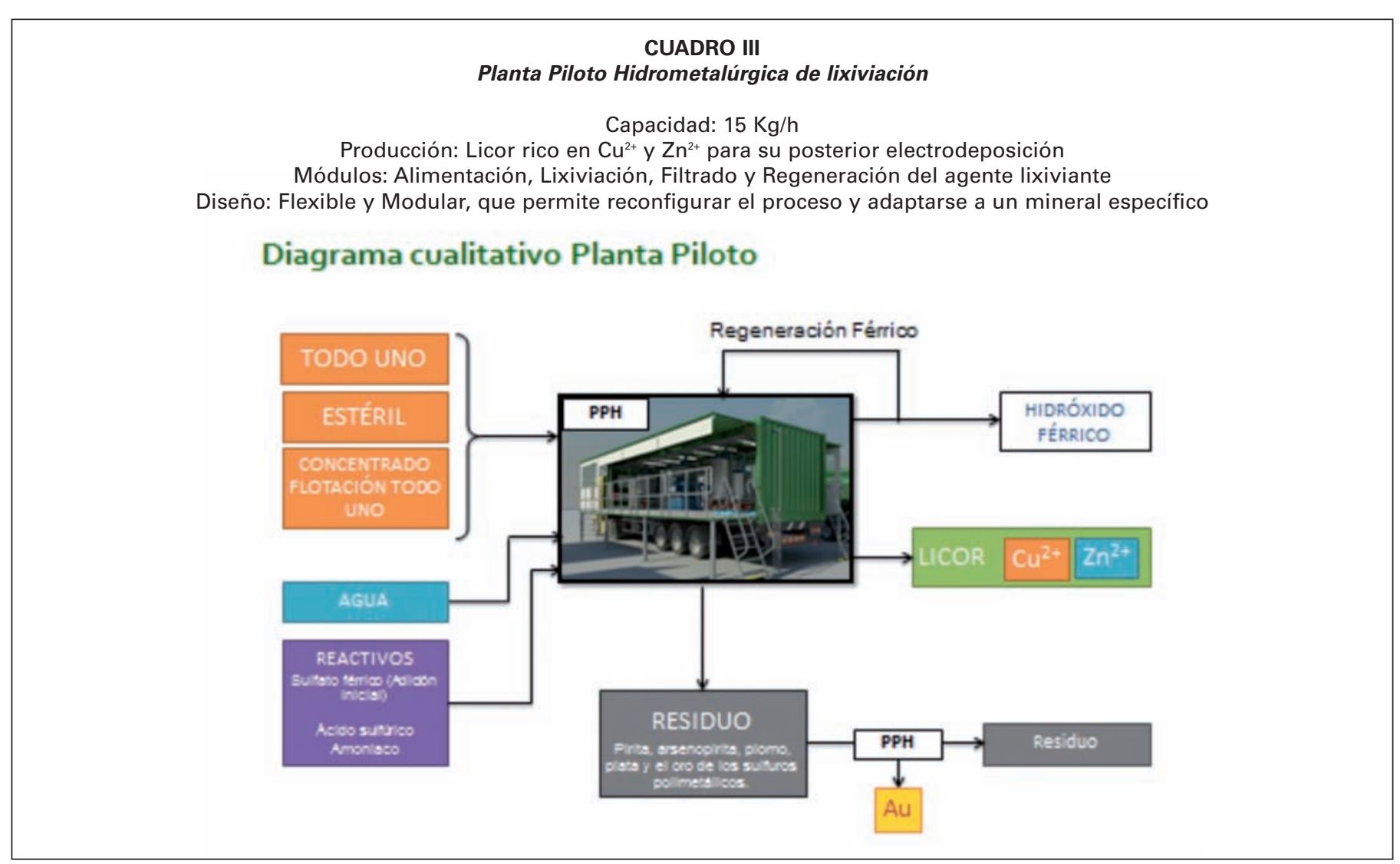


ción del metal precioso contenido en los estériles de los procesos de flotación empleados para la recuperación de cobre, plomo y zinc, en los que la pirita, con todo su contenido en oro, se desecha.

El Instituto Geológico y Minero de España (IGME) viene desarrollando en las dos últimas décadas sucesivas investigaciones destinadas a mejorar los tratamientos hidrometalúrgicos, orientados, por una parte, a un incremento de la recuperación de metales no férricos (Cu-Pb-Zn) en los que es rica la Faja Pirítica $y$, por otra, a posibilitar el aprovechamiento del oro contenido en minerales refractarios al proceso convencional de cianuración. Los avances obtenidos tanto en biolixivación como en los métodos de oxidación a presión atmosférica permiten afrontar con optimismo el desarrollo tecnológico previsto en el futuro inmediato.

\section{Referencias}

Adams, M. 2005. Advances in Gold Ore Processing. Guildford, Australia: Developments in mineral Processing.

Alvarez, J.L. 1996. Revisión crítica de los procesos de beneficio de los sulfuros complejos. Boletín Geológico y Minero, Vol.107-3 y 4, 359-372

Ballester, A., Verdeja, L., Sancho, J. 2000. Metalurgia Extractiva Vol I. Fundamentos. Ed. Síntesis. España.

Ballester, A. 2005. Fundamentos y Perpectivas de las Tenologías Biomineras. Mecanismo de la Lixiviacion. Capítulo 1, 9-24.

Beattie, M.J. y Raudsepp, R. 1988 The Arseno Processan update, Proc. Of Annual Meeting of Canadian Institute of Min. and Metal, Ad. Monten, Canadá.

Beattie, M. J. y Ismay, A. 1990. Appliying The Redox Process to arsenical concentrates, Journal of Metals, January, 31-35.

Berezowski, R., Collins, M., Kerfoot, D., y Torres, N. 1991. JOM, Feb., 9-15.

Boyle, R.W. 1987. Gold. History and Genesis of Deposists. Van Nostrand Reinhold. Reinhold, New York, 675 pp.

Chen, B. y Reddy, R.G. 1990. Roasting Characteristics of Refractory Gold Ores. Advances in Gold and Silver Processing. Processing Symposium At GoldTech4. SMEAIME. Reno, NV (EEUU, 201-214.

Demopoulos, G.P y Papangelakis, V.G. 1989. CIM Bulletin, 85-91

Fair, K.J., et al. 1986. Options in the Nitrox Process, Proc. Int. Symp. On Gold Metall., Conc. Inst. Min. Metall., 279-291.

Fleming, C.A. 1992. Hidrometallurgie, 30, 1-3. 127.

Hong Yon Sohn y Rajendra P. Goel. 1979. Principles of Roasting, Minerals Sci. Engineering, Vol 11, $N^{\circ} 3$.

Iglesias, N., Carranza, F. and Palencia, I. 1998. La biolixiviación como pretratamiento de menas auríferas refractarias en matriz de sulfuros. Revista de Metalurgia, Madrid, 34
Iglesias, N. and Carranza, F. 1996. Treatment of a gold bearing arsenopyrite concéntrate by ferric sulphate leaching. Minerals Engineering. Elsevier. March, 317-330.

Iglesias, N. and Carranza, F. 1994. Refractory gold bearing ores: a review of treatment methods and recent advances in biotechnological technoques. Hydrometallurgy. Elsevier. January, 383-395.

ITGE, 1994. Minería Química. Ed.Instituto Tecnológico Geominero de España.

IGME. 1994. Estudio mineralúrgico preliminar de recuperación de oro contenido en el carbonatado deTharsis, Doc. ITGE $n^{\circ} 1389$.

IGME. 1996. Estudio mineralúrgico de recuperación del oro y cobalto en muestras del stocwork de Tharsis. Doc. IGME $\mathrm{n}^{\circ} 1405$.

IGME. 1997. Tratamiento en planta piloto de concentrados de cobre de Migollas.

IGME. 2003, 2004, 2006. Investigaciones tecnológicas en Planta Piloto Hidrometalúrgica de Tharsis aplicable a los minerales de la Faja Pirítica. Informe interno IGME,

IGME, 2011. Cartografía de recursos minerales de Andalucía. Instituto Geológico y Minero de España y Consejería de Economía, Innovación y Ciencia, Junta de Andalucia, 594 pp.

IGME, 2014, http://www.igme.es/PanoramaMinero/actual/ ORO_14.pdf

La Brooy, S.R., Linge, H.G., and Walker, G.S. 1994. Minerals Engineering. 7, 1213.

Leistel, J.M., Marcoux, E., Deschamps., Y, and Joubert, M. 1998. Antithetic behaviour of gold in the volcanogenic massive sulphide deposits of the Iberian Pyrite Belt. Mineralium Deposita, 33, 82-97.

Leistel, J.M., Marcoux, E., Thièblemont, D., Quesada, C., Sánchez, A., Almodóvar, G.R., Pascual, E. and Sáez, R. 1988. The volcanic hosted massive sulphide deposits of the Iberian Pyrite Belt. Mineralium Deposita, 33, 2-30.

Marcoux, E., Moëlo, Y. and Leistel, J.M. 1996. Bismuth and cobalt minerals as indicators of stringer zones to massive sulphide deposits, Iberian Pyrite Belt. Mineralium Deposita, 31, 1-26.

Long, H.G. and Dixon, D. 2004. Pressure oxidation of pyrite in sulfuric acid media a Kinetic study. Hidrometallurgy, 73, 3-4, 335-349.

Marcoux, E. Moelo, Y., and Leistel, J.M. 1996. Bismuth and cobalt minerals as indicators of stringer zones to massive sulphide deposits, Iberian Pyrite Belt. Miner. Dep, 31: $1-26$

Marsden, J. and House, C. 2006. The Chemistry of Gold Extraction. Ed. Ellis Horwood Series.

Norwood, A.F., 1939. Roasting and treatment of auriferous flotation concentrate. Inst. Min. and Met. Proc. N116, 391-412.

Papangelakis, V. and Demopoulos, G. 1989. Recent Advances in Refractory Processing. CIM Bulletin. 82 (931), 85-91

Pardave, W. and Beltrán, A. 2007. Lixiviación de mineral aurífero de vetas Santander, con sales oxidantes en medio ácido. Sciencia y Technica año XIII, 36. Universidad Tecnológica de Pereira. 
Peters, E. 1992. Hidrometallurgical process innovation. Hidrometallurgy 29, 431-459

Rodriguez,,Y., et al. 2001. La biolixiviación al comienzo del siglo XXI. Rev. Metal. Madrid, 37, 616-627.

Ruiz de Almodóvar, G. and Sáez, R. 1992. Yacimientos de sulfuros masivos de la Faja Pirítica Sur Ibérica. In: García Guinea, J. and Martínez Frías, J. (coord.) Recursos minerales de España.CSIC, Madrid, 1309-1324.

Strauss and J.S. Beck, J.S. 1990. Gold mineralisations in the SW Iberian Pyrite Belt G.K. Mineral. Deposita 25, 237245

Udupa, A., Kawatra, S., and Prasad, M., 1990. Developments in gold leaching: a literatura survey. Mineral Processing and Extractive Metallurgy Review, 7, 115-135.

Van Aswegen, P.C. 1993. Pro. Biomine 93. Australian Mineral Foundation, Adelaida, Australia, Cap 15.

Van Lierde. 2002. Fundements des procédés pyrométallurgiques. Universite Catholique de Louvain.

Velasco Roldán, F. 2014. El oro asociado a los sulfuros masivos de la Faja Pirítica Ibérica. Macla. Revista de la Sociedad Española de Mineralogía, 19.

Yannopoulos, J.C. 1991. The Extractive Metallurgy of Gold. Treatment of refractory gold ores.79-114. Van Nostrand Reinhold, N.Y. 79-114.

Recibido: julio 2018

Revisado: noviembre 2018

Adeptado: febrero 2019

Publicado: junio 2019 
